\title{
A interculturalidade no cotidiano de uma escola indígena
}

\author{
Eunice Dias de Paula
}

\begin{abstract}
RESUMO: Este artigo aborda a questão da interculturalidade como categoria constitutiva de uma escola indígena. Contrastando com a concepção colonialista, etnocentrista, que permanece até os dias atuais, surgem outras possibilidades que consideram a autonomia dos povos indígenas na condução de seus próprios projetos educacionais.
\end{abstract}

Palavras-chave: Educação intercultural-bilíngue, escola tapirapé, recursos didáticos, autonomia escolar indígena, assimilação

\section{Introdução}

Quando se fala em interculturalidade, a idéia que nos vem à mente é a de que duas ou mais culturas estão se relacionando de alguma forma. A escola, quando se instala numa comunidade indígena - quer a pedido desta, quer à custa de ações marcadas por imposições colonialistas, ainda presentes em nossos dias -, traz no seu cerne essa problemática, visto ser ela uma instituição tão caracteristicamente criada pelas sociedades ocidentais.

A dimensão da interculturalidade está hoje colocada como um dos aspectos desejáveis para uma escola indígena, tida mesmo como

* Assessora pedagógica da Escola Indígena Tapirapé. Mestranda em Estudos Lingüísticos-
UFG. Membro do Conselho Indigenista Missionário (Cimi). E-mail: xeretyma@persogo.com.br 
uma das condições necessárias para que seja respeitada a especificidade da educação escolar indígena, como transparece nitidamente numa das metas elaboradas recentemente para o Plano Nacional de Educação: "Criar, dentro de um ano, a categoria oficial de 'escola bilíngüe', para que a especificidade do modelo de educação intercultural e bilíngüe seja assegurada."

O binômio intercultural e bilíngüe é considerado como constitutivo da categoria "escola indígena". Essa preocupação em afirmar os currículos educacionais indígenas como interculturais nasce de uma situação já existente de fato. Ou seja, antes de a escola ser intercultural, as sociedades indígenas já estão se relacionando com a sociedade não-indígena, desde o momento do contato. E o modo como ocorrem essas relações se reflete no cotidiano da escola. Não é outra a razão de só recentemente esse adjetivo aparecer qualificando a escola indígena, coincidindo com a época em que o modelo de educação integradora, implantado desde o início da colonização em nosso país, começou a ser questionado pelas comunidades indígenas e seus aliados. Nesse modelo, as questões que diziam respeito às culturas indígenas não se colocavam, pois se a intenção era a assimilação dos índios à "comunhão nacional", conseqüentemente a escola deveria ser um dos instrumentos dessa integração, e essa perspectiva estaria, inevitavelmente, presente nos currículos, transplantados dos modelos aplicados nas escolas da sociedade majoritária.

A exigência da interculturalidade nos currículos das escolas indígenas é uma constante não só no Brasil. Na América Latina, vários documentos expressam essa preocupação, como a proposta da Direção Nacional de Educação Intercultural Bilíngüe do Equador (Dineib) e a Lei da Academia das Línguas Maya, da Guatemala, analisadas por Moya (1994).

Entretanto, se, por um lado, há um consenso quase unânime de que a escola indígena deva ser intercultural, por outro, parece haver várias concepções sobre o modo como a interculturalidade se concretiza no dia-a-dia de uma escola indígena. Por isso, parece-nos importante aprofundar a discussão sobre este assunto, colocado na ordem do dia quando se trata de educação escolar indígena. Para esta reflexão, o referencial básico será a Escola Tapirapé, onde a autora participa do trabalho educacional, juntamente com Luiz Gouvêa de Paula, desde 1973. 


\section{A interculturalidade e a questão do conhecimento}

A interculturalidade, quando pensada no cotidiano de uma escola indígena, está intrinsecamente ligada à questão dos conhecimentos. Não se propõe, por exemplo, que para garantir o caráter intercultural deva haver necessariamente professores não-índios e indígenas trabalhando lado a lado na sala de aula. Ou que o prédio da escola deva conter características arquitetônicas indígenas e ocidentais, ao mesmo tempo.

Já vimos como a escola, no modelo assimilacionista, lidava com essa questão - os conhecimentos adequados às suas finalidades eram os trazidos pelos europeus. Os povos indígenas foram considerados como incapacitados, em conseqüência, teriam de receber tudo dos que chegavam. Gandavo, um dos cronistas quinhentistas, ao comentar o idioma dos indígenas, assim se expressou: "não se acha nele $F$, nem $L$, nem $R$, cousa digna de espanto, porque assim não têm Fé, nem lei, nem rei". A ausência de autoridades políticas fortemente centralizadas, de códigos escritos e de ídolos aos quais devotassem cultos, isso tudo acrescido do fato de a língua dos grupos tupi, com os quais os portugueses entraram em contato por primeiro, não possuir os fonemas /f/, /l/ e /r/, levou à conclusão de que os povos indígenas não possuíam nem leis, nem reis, nem fé e, é claro, nem conhecimentos, nem educação! É óbvio que o modelo de comparação pautava-se por parâmetros europeus, transparecendo nesses comentários uma visão de mundo marcadamente etnocentrista. Assim se inicia um longo período em que a educação foi planejada para os índios, seguindo um modelo transplantado de outro povo, de outro mundo, sem considerar a realidade dos povos indígenas, seus conhecimentos, suas cosmovisões. A idéia era de que os nativos estavam num estado de "cera mole", fácil de ser moldada e, para essa tarefa tão simples, não se necessitava de mestres muito competentes, como transparece numa carta de Nóbrega: "Acá pocas letras bastan, porque es todo papel blanco y no ay más que escrivir a plazer (...)".3

Essa concepção do índio como alguém incapacitado, sem conhecimentos e que, por isso, tem de receber tudo de alguma outra sociedade, de outros povos, que, por sua vez, se consideram "superiores", caracteriza um processo de escolarização desenvolvido para atender a interesses colonialistas: a invasão e a posse da terra, a "domesticação" dos índios para o trabalho escravo etc. Infelizmente, essa concepção se encontra ainda bastante presente nas relações entre o Estado brasileiro e os povos indígenas, 
sobremaneira nos assuntos ligados à educação escolar. São inúmeras as escolas indígenas obrigadas a seguir programas curriculares determinados por secretarias municipais de educação, que exigem cumprimento de horários, calendários, modos de avaliação das crianças e outros quesitos nada compatíveis com os processos educativos presentes nas diferentes sociedades indígenas. Embora a Constituição Federal de 1988 tenha reconhecido o direito desses povos a uma educação específica e diferenciada (arts. 231, 210 e 215), no dia-a-dia, os professores e as comunidades indígenas continuam a sofrer pressões inaceitáveis, que ferem os mais elementares direitos de qualquer ser humano, como foi denunciado em recente congresso promovido pelas Universidades Federal do Mato Grosso do Sul e Católica "Dom Bosco"” para discutir sobre educação escolar indígena. Professores indŕgenas de abumas áreas guarani-kaiowá, convidados pela coordenação do evento, foram impedidos de participar, por ordem dos secretários de educação municipais! Como pensar a interculturalidade numa escola situada nesse contexto? Evidencia-se muito claramente que as relações entre as sociedades indígenas e a sociedade majoritária, dominadora, estão acontecendo de maneira extremamente assimétrica, desigual, ainda pautando-se pelos parâmetros impositivos implantados pelos colonizadores europeus desde que aqui chegaram. O que acontece ainda hoje na maioria das escolas existentes em áreas indígenas é o reflexo de uma situação sociopolítica mais abrangente, que marca as relações entre os povos indígenas e nossa sociedade. O currículo, assim, se traduz numa imposição cultural. Por outro lado, a visão etnocentrista escamoteia a enorme apropriação de bens e conhecimentos dos povos ameríndios desde que os primeiros europeus aqui aportaram: minérios, alimentos como batata, milho, tomate, cacau, e produtos manufaturados, como a rede. Os conhecimentos agrícolas dos povos indígenas permitiram uma melhoria alimentar sem precedentes na história da Europa. A rede, por sua praticidade, foi utilizada até em campanhas de guerras, como comenta Jean de Lèry, um dos cronistas quinhentistas. Mas isso quase não é abordado nas escolas e raramente aparece em livros didáticos, perpetuando a visão dos povos indígenas como seres "selvagens, primitivos, incapazes".

\section{Trilhando outros caminhos}

Apesar da violência e do desrespeito que têm marcado as ações dos colonizadores perante os povos indígenas nesses cinco séculos, 
constatamos que essas sociedades - as que, felizmente, sobreviveram ao extermínio físico - desenvolveram estratégias para resistir aos invasores, como enfatiza Melià:

\begin{abstract}
Estos pueblos no sólo superaron la prueba del período colonial, sino también el de los embates de la asimilación e integración de tiempos más recientes. ¿Cómo lo lograron? Y ¿hasta qué punto conseguirán mantener esa alteridad e identidad diferente? Los pueblos indígenas han mantenido su alteridad gracias a estrategias, de las cuales una es la acción pedagógica. En otros términos: ha seguido habiendo en estos pueblos una educación indígena que permite que el modo de ser y la cultura se reproduzcan en las generaciones nuevas, pero también se encare con relativo éxito nuevas situaciones. (Melià 1998)
\end{abstract}

Essas ações pedagógicas, que têm possibilitado a manutenção das alteridades, revestem-se de características diferenciadas segundo a cultura própria de cada sociedade indígena. Assim, a educação tapirapé é diferente da educação do povo carajá, que, por sua vez, difere da xavante. Entretanto, mesmo considerando essas diferenças, podemos encontrar elementos que permitem visualizar processos educacionais em curso em cada um desses povos. Há espaços propícios à socialização dos novos membros, como a casa, o pátio de realização dos rituais, ou as casas cerimoniais. A família extensa, via de regra, ocupa-se da educação das crianças, embora isso não impeça a ação de mestres especializados em determinados saberes, como é o caso dos xamãs. $O$ ciclo de vida das pessoas é marcado com momentos celebrados festivamente pela comunidade, como nos rituais de passagem de uma idade para outra. Entre os tapirapé, as crianças, a partir do desmame, agem com progressiva autonomia e independência dos adultos, a tal ponto que Baldus, um etnólogo que esteve com eles em 1935 e 1947, ao comparar o comportamento delas em relação às crianças alemãs, disse que estas "apresentavam muito mais 'infantilidade' que as crianças índias (...) a criança índia é determinada" (Baldus 1970, p. 286). Os ensinamentos são diferenciados para os rapazes e as moças, segundo a divisão social do trabalho, e há momentos formalizados nos quais a educação acontece de forma mais intensiva, sobretudo nos rituais de passagem, quando os rapazes deixam de ser considerados meninos e integram o grupo dos homens, podendo freqüentar a takãra, grande casa cerimonial, cujo 
acesso é vedado às mulheres. Para as jovens, esses momentos ocorrem por ocasião da menarca, quando ficam reclusas em casa, sob os cuidados da mãe, das tias e das avós. Ao terminar o período do sangramento menstrual, a nova moça é enfeitada com pinturas e adornos especiais e apresentada à comunidade. Marcando essas mudanças de fases da vida ocorre troca de nomes, tanto para os rapazes como para as moças.

A educação, pensada como um processo contínuo, tem como objetivo socializar os novos membros e isso é encarado como uma responsabilidade do grupo todo. O respeito e o incentivo à atitude autônoma do educando caracterizam as ações pedagógicas necessárias ao êxito do processo.

Entretanto, o momento do contato com a nossa sociedade marca indelevelmente esses povos, pois representa a invasão física de seus territórios, impossibilitando-Ihes a continuidade da vida tal como se dava antes. Epidemias causadas por doenças, antes desconhecidas, dizimam grande parte da população; o roubo organizado de madeiras, de minérios, de animais e outros bens espolia e depreda as terras ocupadas tradicionalmente pelos povos indígenas. É necessário uma reorganização diante da nova situação imposta pelo contato para tentar garantir a sobrevivência, e é nesse contexto que, em muitos casos, surge a solicitação pela escola. Assim, essa instituição tão típica de nossa sociedade é reivindicada como instrumento de defesa na luta contra as vicissitudes enfrentadas na nova situação, como se pode depreender no caso dos tapirapé.

\section{Os tapirapé e a escola}

Os atuais tapirapé são remanescentes de um povo que contava aproximadamente com 1500 pessoas no início do século XX. Por volta de 1952 , estavam reduzidos a apenas 47 pessoas, quando as Irmãzinhas de Jesus, religiosas católicas de origem francesa, chegaram à região para conviver com eles. Epidemias de gripe, varíola e sarampo, além de repetidos ataques dos caiapós, os levaram à beira da extinção. A ação paciente e respeitosa das Irmãzinhas, assegurando uma contínua assistência à saúde, possibilitou uma recuperação populacional surpreendente e animadora. Hoje somam 420 pessoas.

Entretanto, na década de 1960, período da ditadura militar, a política governamental de ocupação da Amazônia favoreceu a instalação 
de grandes latifúndios na região norte do Brasil, sustentando o processo por meio dos incentivos fiscais repassados pela Superintendência do Desenvolvimento da Amazônia (Sudam). Em relação aos povos indígenas e posseiros que já viviam na região, isso se traduziu num acirramento da luta pela posse da terra, conflito que, como sabemos, permanece até hoje no Brasil. Os tapirapé, que começavam a se reorganizar depois do violento processo de perda populacional, depararam com novos problemas: fazendas agropecuárias começaram a se instalar em seu território, destruindo rapidamente as matas para fazer pastos para o gado. A necessidade de demarcar uma área se fez urgente e é nesse contexto que os tapirapé pediram escola, como algo capaz de lhes fornecer instrumentos valiosos na luta pela defesa do território, como por exemplo decifrar os mapas sobre os quais os fazendeiros e funcionários da Funai discutiam os limites da área indígena ou viajar a Brasília para defender seus direitos junto ao governo.

Não é difícil constatar a extrema desigualdade presente nessa situação de confronto entre as duas sociedades, entre as duas culturas. O planejamento de um projeto educacional não poderia ignorar essa situação. Se a escola quisesse atender às expectativas dos tapirapé, ela não poderia simplesmente repetir o modelo assimilacionista, a educação "bancária" no dizer de Paulo Freire, na qual se dá um simples repasse de conhecimentos tidos como prontos e acabados para o aluno, considerado como um mero receptor passivo. No caso das escolas indígenas, ainda há o agravante de tratarse de culturas diferentes, ou seja, estamos lidando com conhecimentos produzidos por sociedades diferentes, em situações históricas específicas. Se só os conhecimentos da cultura majoritária forem valorizados, continuaremos a considerar os povos indígenas como incapazes de produzir conhecimentos. Os aportes teóricos colocados por Freire, na época intensamente perseguido pelos militares no poder, já que não concebia a educação como algo isolado de um movimento pela transformação das condições de vida dos trabalhadores, serviram de valiosos referenciais para o trabalho pedagógico a ser desenvolvido entre os tapirapé. Um dos postulados básicos de Freire é o de que o educando deve ser considerado como sujeito de seu próprio processo de aprendizagem, partindo de sua própria palavra, sua língua, sua cultura, sua situação histórica, fazendo uma leitura do mundo e não apenas uma decodificação de sinais gráficos, desligados da vida das pessoas. Num movimento dialético 
a leitura do mundo precede sempre a leitura da palavra e a leitura desta implica a continuidade da leitura daquele (...) a leitura da palavra não é apenas precedida pela leitura do mundo mas por uma certa forma de "escrevê-lo" ou de "reescrevê-lo", quer dizer, de transformá-lo através de nossa prática consciente. (Freire 1985, p. 22)

A postura de reflexão crítica sobre a própria realidade levou à discussão de temas pertinentes às questões vividas pelos tapirapé naquele momento: ${ }^{5}$ quem eram eles, sua história, o porquê da demarcação da terra, a saúde, a alimentação... e até mesmo o tema "lazer" foi discutido! Entretanto, na hora da discussão, percebemos o equívoco, pois na cultura tapirapé o lazer não é visto da mesma forma que nós o vemos, com tempo e espaço definidos. Todas as atividades são feitas dentro de um espírito de bom humor e alegria. A palavra escolhida para esse tema foi xigy, pescaria feita com timbó em pequenos lagos durante a seca. Acontece que essa pescaria é, antes de tudo, uma atividade econômica, de obtenção de alimento, mesmo que feita de uma maneira que se assemeIha a um grande piquenique. Isso comprova o que o grande mestre sublinhou: "Não há prática pedagógica que não parta do concreto cultural e histórico. Experiência e prática não se transplantam, se re-inventam, se re-criam" (Freire 1982).

Vivendo a interculturalidade no dia-a-dia

Justamente por ser histórico, o concreto sociocultural dos tapirapé foi mudando. Em 1983, eles conseguiram a demarcação da área pela qual lutaram por mais de dez anos. ${ }^{6}$ Hoje se encontram num processo de recuperação da área do Urubu Branco, território tradicional que foram obrigados a deixar diante da situação de quase extermínio vivenciada por volta da metade do século. Em 1988, a escola foi reconhecida como escola estadual por solicitação deles, que queriam ter seus estudos reconhecidos como os dos tori (não-índios). A proposta curricular elaborada para esse reconhecimento foi longamente discutida com a comunidade e, ao tratar dos aspectos relativos à aquisição dos conhecimentos, aponta um caminho metodológico no qual os conhecimentos dos tapirapé não estejam ausentes do cotidiano escolar: 
(...) sem colocar os nossos conhecimentos como superiores, senão estaremos esvaziando e até destruindo elementos culturais que sustentam a identidade étnica deste povo (...), a escola não pode menosprezar o saber próprio da comunidade indígena. A partir do conhecimento do índio sobre biologia, botânica, zoologia, astronomia etc., os conhecimentos nossos também serão apresentados, mas de uma maneira comparativa e não como verdades absolutizadas. (Escola Tapirapé 1986, pp. 4-5)

Vejamos como tais parâmetros curriculares se concretizam na sala de aula, focalizando trechos dos Relatórios de Atividades redigidos pelos professores tapirapé: ${ }^{7}$

Recorte A:

Quando acabamos de estudar esse assunto sobre o arroz, nós começamos estudar outro tema que é o porcão. Os alunos desenharam o pessoal matando porcão. Porque teve muito pessoal que estava matando porcão do mato. Então nós estudamos sobre ele. Eles escreveram as histórias deles. Nós treinamos lendo essas histórias que os alunos escreveram sobre o porcão. Nós fizemos com os alunos vários exercícios para eles fazerem. Também nós fizemos uma dramatização com esse assunto sobre o porcão. Nós dividimos em três grupos para fazer essa dramatização. Porque um grupo ficou como cachorro latindo no porcão e outro grupo ficou como porcão correndo atrás do cachorro. Também teve um grupo sendo gente matando porcão. Os alunos gostaram de brincar com essa dramatização. (Professor Júlio César Tawy'i , 2ª série, 1992)

\section{Recorte B:}

(...) Fizemos também uma observação sobre o filhote de marimbondo. Essa observação foi feita com os meus alunos. Toda semana de estudo observamos o filhote de marimbondo. Essa observação era somente para saber com quantos dias os filhotes dos marimbondos voam e de que eles se alimentam na sua casinha (...). (Prof. Kamoriwa'i Elber, $3^{\mathrm{a}}$ série, 1989) 


\section{Recorte C:}

(...) Depois nós passamos estudar também sobre classificação dos peixes. Que tipo de peixe nós comemos aqui na aldeia e que tipo de peixes que nós não comemos. Aí os alunos contaram muito tipo de peixes que nós comemos e pouco peixes que nós não comemos (...). (Prof. Kaorewygi Reginaldo, $4^{\mathrm{a}}$ série, 1992)

\section{Recorte D:}

No tema da onça, primeiro os alunos leram o texto na cartilha, fizeram leitura coletiva, leitura individual, copiaram esse mesmo texto no próprio caderno. Depois de copiar tudo acharam palavras novas e circularam só o nome da onça no texto. Em seguida desenharam na folha branca e trabalharam em grupo para fazer um desenho maior com recorte e colagem no cartaz. Os alunos adoraram de trabalhar em grupo e fazer desenho com revista velha. Fizeram dramatização, depois chamamos o velho para contar a história da onça para os alunos na sala de aula. E essa história nós gravamos para ficar na escola para as crianças ouvirem e saber como foi a história da onça com tamanduá. Nessa história gravamos até uma música que fizemos para cantar no recreio todo dia quando estudamos (...). (Prof. Josimar leremy'i, $1^{\underline{a}}$ série, 1994)

Nesses excertos dos relatórios elaborados pelos professores transparece a prática pedagógica tal como vem sendo vivenciada na escola. Os temas a serem tratados em sala de aula como objeto de estudo são escolhidos com base em fatos vivenciados pelas crianças: a caçada de porcão, os filhotes de marimbondo, a onça, os peixes - todos esses assuntos dizem muito para os alunos, são plenos de significados dentro do contexto cultural tapirapé.

Os recursos didáticos - as chamadas estratégias - não são absolutizados em si mesmos. Eles entram no conjunto da aula, propiciando o desenvolvimento do tema, com a intensa participação dos alunos. Alguém acostumado ao mutismo compulsório e à "ordem" reinantes numa sala de aula em que ainda impere a figura do professor autoritário se espantará ao ver a aparente "desordem" de uma sala de aula tapirapé. Dramatizações, trabalhos em grupo, pesquisas, montagem de cartaz com 
recorte e colagem, desenho, pinturas, audição de histórias, música... as crianças ficam muito pouco paradas. Detalhe: percebe-se pelos relatos A e D que elas gostam de ficar na escola!

O livro didático - no caso, a cartilha tapirapé, com textos e ilustrações feitos pelos alunos - não é descartado, mas usado como apoio ao trabalho de alfabetização, como descrito no relato $D$. A presença do veIho na escola, contando as histórias tradicionais (relato D), é outro ponto que merece ser destacado, já que por aí podemos constatar que a educação tradicional tapirapé não precisa estar em situação de ruptura em relação à escola. Novos meios, como o gravador, vão sendo integrados para facilitar a transmissão dos mitos antes contados só oralmente. ${ }^{8}$

A atitude de constante observação já é própria dos tapirapé. Entretanto, ao incentivar a pesquisa (relatos B e C), a escola vai propor um passo além: a observação é planejada e seus resultados serão sistematizados em classificações segundo os critérios culturais próprios, usando recursos gráficos, tabelas etc. Assim, os suportes utilizados na ciência ocidental podem ser perfeitamente aplicáveis aos conhecimentos tapirapé sobre a natureza, mostrando formas diferentes de organização dos saberes:

Como o currículo parte da construção do conhecimento de uma forma global e coletiva, os conteúdos precisam estar inter-relacionados, partindo sempre dos etnoconhecimentos de cada povo, intensificando as dimensões interculturais. A metodologia é parte integrante do currículo, e deve ser sempre pensada a partir do sistema educacional próprio de cada etnia. (Cimi 1993, p. 9)

Outro aspecto a ser ressaltado é que os temas não são sempre os relacionados à vida animal ou vegetal, como poderia parecer à primeira vista, dada a seleção dos trechos transcritos acima. Vejamos o relato de uma aluna, após uma excursão realizada pela escola à Serra do Urubu Branco, em agosto de 1991, quando os tapirapé ainda não haviam retornado a essa área:

\section{Recorte E:}

Quando nós fomos no Urubu Branco, vimos várias fazendas e muito gado nos pastos. Os brancos derrubaram a mata que tinha na bei- 
ra do Ipirakwãri. Agora nós fomos observar só pasto no lugar da mata. E deixaram só um pouquinho de mata para Ipirakwãri. E daí que a água desce sem a mata. No Urubu Branco os brancos fizeram um pasto muito grande para os gados. Na estrada do Xani'ãona nós vimos os pau-brasil cortados. Os brancos estão acabando o pau-brasil do Urubu Branco. (Tamanãxowoo, aluna da $5^{\mathrm{a}}$ série, 1991)

É notável a percepção da garota em relação aos problemas ambientais que os desmatamentos realizados pelas fazendas de gado estão provocando na região, inclusive na relação entre a presença das matas de galeria e o ribeirão Ipirakwãri. Visualizam-se, também, os problemas sociais advindos dos modos de ocupação e uso do solo postos em prática pelas fazendas da região. Vemos, assim, que assuntos que não se relacionam com o modo de vida tradicional não precisam ser artificialmente trazidos para dentro da escola. Eles estão presentes na vida atual dos tapirapé e, por isso, são colocados como temas de estudo pelos alunos ou pelos professores. O que acontece na sala de aula não está desvinculado do que está acontecendo na vida da comunidade e, se acreditarmos que a educação indígena continua existindo como processo pedagógico capaz de fomentar a identidade étnica de um povo, veremos que o que está ocorrendo é uma verdadeira apropriação da escola, integrando-a no dinamismo próprio dos sistemas educativos, como propõe Melià:

Em vez de Educação Escolar Indígena, por que não pensamos Educação Indígena na Escola? Há duas maneiras de se pensar a escola: levar a escola à área indígena e, eventualmente, "adaptála". A escola entra na comunidade indígena. A outra maneira traz uma proposta radicalmente diferente: é pensar como a educação indígena entra na escola! Só aí vamos ter educação bilíngüe de fato. Fazer isso não é enfraquecer a escola, é o contrário. É o único jeito de a escola ser indígena. (Melià 1997; grifo nosso)

\section{Considerações finais}

A mudança de perspectiva - em vez da escola em área indígena, tornar-se uma escola indígena de fato, uma escola inserida na comunidade 
educativa própria de cada povo - traz novas dimensões para a discussão acerca da interculturalidade. Interculturalidade que está presente na escola indígena porque as relações entre as duas sociedades estão, efetivamente, permeando a vida de qualquer grupo indígena na situação pós-contato. A própria existência da instituição escolar já exemplifica esse fato. Entretanto, como essas relações estão, via de regra, marcadas pelo conflito, urge ter presente que a autonomia desses povos nas decisões dos projetos educacionais que lhes dizem respeito constitui um ponto essencial se almejamos estabelecer relações menos assimétricas numa situação intercultural.

O reconhecimento dessa autonomia passa por uma negação do modelo assimilacionista de educação implementado desde a época coIonial que, como vimos, tinha como pressuposto subjacente a suposta "incapacidade" dos índios. Infelizmente, essa concepção permanece até os dias atuais, quando ainda se planejam ações para as escolas indígenas, mantendo-os assim numa posição de tutelados, ignorando o direito à alteridade, já garantido na Constituição de 1988. O etnocentrismo de nossa sociedade permanece através dos séculos, apesar de que, se nos dedicarmos à analise de como os povos indígenas interagem conosco, veremos que eles desenvolvem mecanismos seletivos para se apropriarem de instituições como a escola, ressignificando-as segundo suas necessidades, conforme explicitou o professor guarani Valentim Pires:

Com a ajuda da escola, com uma educação que realmente responda às nossas necessidades, queremos reconquistar a autonomia socioeconômica e cultural e sermos reconhecidos como cidadãos etnicamente diferentes. Não queremos que a escola sirva para desestruturar nossa cultura e nosso jeito de viver; que não passe mais para nossas crianças a idéia de que somos inferiores e que, por isso, precisamos seguir o modelo dos brancos para sermos respeitados. (Pires 1998; grifo nosso)

Assim, podemos concluir que a interculturalidade não está num modelo que prioriza ora os conhecimentos acumulados pela sociedade ocidental, ora os conhecimentos produzidos pelas sociedades indígenas, mas na garantia de a escola poder ser um espaço que reflita a vida dos povos indígenas hoje, com as contradições presentes nas relações entre as diferentes sociedades, com a possibilidade de ser integrada nos pro- 
cessos educativos de cada povo e, assim, ser administrada segundo os parâmetros específicos desses processos, como sublinhado por Freire:

(...) a transformação não é só uma questão de métodos e técnicas. Se a educação libertadora fosse somente um questão de métodos, então o problema seria mudar algumas metodologias tradicionais por outras mais modernas. Mas não é esse o problema. $A$ questão é o estabelecimento de uma relação diferente com o conhecimento e com a sociedade. (Freire e Shor 1996; grifo nosso)

\section{Notas}

1. Meta ํo 6, Capítulo 8: Educação Indígena. Plano Nacional de Educação, MECInep, 1998, p. 63.

2. Gandavo 1924, apud Orlandi e Souza 1988, p. 36.

3. Nóbrega, I, p. 136, apud Viveiros de Castro 1992, p. 9

4. I Congresso Internacional de Educação Escolar Indígena, Dourados, MS, 2327 de março de 1998.

5. Há que se considerar que, nesse primeiro momento, a escola atendia os tapirapé adultos.

6. Área indígena tapirapé-carajá, com aproximadamente 66.000 ha, situada no município de Santa Terezinha (MT).

7. Recortes extraídos da monografia "Escola Tapirapé: Processo de apropriação de educação escolar por uma sociedade tupi", apresentada pela autora como requisito de conclusão do curso de Pedagogia da Universidade Estadual de Mato Grosso (Unemat).

8. A presença do velho contando os mitos na escola, fato questionável em outras situações, no caso tapirapé tem sido estimulado pela própria comunidade, em vista do reduzido número de pessoas idosas em comparação com a numerosa população infantil.

\section{The daily intercultural of an indigenous school}

ABSTRACT: This article emphasizes the intercultural as a constitutive category of an indigenous school. Contrasting with the colonial conception, ethnocentric, that remains to the present days, other possibilities come up that consider the autonomy of indigenous people of conducting their own educational projects. 
Bibliografia

BALDUS, Herbert. Tapirapé: Tribo tupi no Brasil central. São Paulo: Companhia Editora Nacional, 1970.

CIMI - Conselho Indigenista Missionário. "Concepção e prática da educação escolar indígena". Cadernos do Cimi 2. Brasília, 1993.

ESCOLA INDíGENA TAPIRAPÉ. "Proposta curricular". Santa Terezinha (MT), 1986. (Mimeo.)

FREIRE, Paulo. Assessoria à Assembléia Regional do Cimi - Regional MT. Cuiabá, 1982. (Mimeo.)

. A importância do ato de ler - Em três artigos que se completam. São Paulo: Cortez/Autores Associados, 1985.

FREIRE, Paulo e SHOR, Ira. Medo e ousadia: O cotidiano do professor. São Paulo: Paz e Terra, 1996.

LÈRY, Jean de. Viagem à terra do Brasil. São Paulo: Martins Fontes/Edusp, 1972.

MELIÀ, Bartomeu. Educação indígena e alfabetização. São Paulo: Loyola, 1979.

"Ação pedagógica e alteridade: Por uma pedagogia da diferença". Comunicação apresentada à Conferência Ameríndia de Educação e Congresso de Professores Indígenas do Brasil. Cuiabá, 1997.

. "Educación indígena en la escuela". Palestra proferida no I Congresso Internacional de Educação Indígena. Dourados (MS), 1998.

MOYA, Ruth. "Heterogeneidade cultural e educação: Encruzilhadas e tendências". Encontro Latino-americano de Jovens e Adultos TrabaIhadores. MEC-Inep-SEF/Unesco, 1994.

ORLANDI, E.P. e SOUZA, T.C.C. "A língua imaginária e a língua fluída: Dois métodos de trabalho com a linguagem". In: ORLANDI, E.P. (org.). Política lingüística na América Latina. Campinas: Pontes, 1988.

PAULA, E.D. "Escola Tapirapé: Processo de apropriação de educação escolar por uma sociedade tupi". Monografia final do curso de pedagogia apresentada à Universidade Estadual de Mato Grosso (Unemat), 1997. 
PAULA, E.D. e PAULA, Luiz G. "A escola tapirapé". In: Comissão Pró-Indio SP. A questão da educação indígena. São Paulo: Brasiliense, 1981.

PIRES, Valentim. "Discurso de abertura". I Congresso Internacional de Educação Indígena. Dourados (MS), 1998.

VIVEIROS DE CASTRO, E.B. O mármore e a murta: Sobre a inconstância da alma selvagem. Rio de Janeiro: Museu Nacional/UFRJ, 1992.

WAGLEY, Charles. Lágrimas de boas-vindas: Os índios tapirapé do Brasil central. Belo Horizonte: Itatiaia/Edusp, 1988. 